\title{
A social-product-process framework for construction
}

Žiga Turk and Robert Klinc

Faculty of Civil and Geodetic Engineering, University of Ljubljana, Ljubljana, Slovenia

Published in:

BUILDING RESEARCH \& INFORMATION, https://doi.org/10.1080/09613218.2019.1691487

This paper introduces a new framework for the understanding, modelling and software engineering in construction information activities such as designing. The current framework is based on understanding that products are the results of processes, which are performed by actors. Such frameworks are influenced by the available technology. The Internet of today is supporting also other kinds of human activities: communication and social interactions among humans. The construction industry uses them as well but without having a proper understanding of their role. There is a gap within the current framework. In this paper, the relevant theories to specify this gap in terms of what could exist in theory and what is offered by technology are analysed. As a result, a new framework of construction information activities that fills the gap is proposed. The key concepts and relations among them are identified and elaborated within the existing framework. The framework introduces the third major integrative element of the otherwise fragmented construction information activities - the social network - the existing two being the physical building and its digital twin. The framework provides a theoretical and conceptual basis for designing, planning, creating, monitoring and evaluating construction-related on-line services that include a strong social component and use social media services.

Keywords: construction; process modelling; workflow; social media; BIM.

\section{Introduction}

The aim of this paper is not to discuss how technology can help engineers and architects perform their day to day activities but how it changes the way we think and understand 
what we do and consequently what we would want to do with technology. The thinking and understanding relies on a framework which can be more or less explicit and formal. The current framework is built on the assumption that construction products are the results of the construction processes which are performed by actors. This has origin in ISO 9000 (ISO, 2015) and was adopted in the IFC standard (buildingSMART, 2018) for information products such as designs and plans as well. It is shown in Figure 1. It is simple but fails to take into account the progress in internet technology and social media over the last decade. It takes only partial stock of understanding the role of technology, paradigms of human activity and the interaction between the two as established in linguistics, philosophy, social science, communication and design theory.

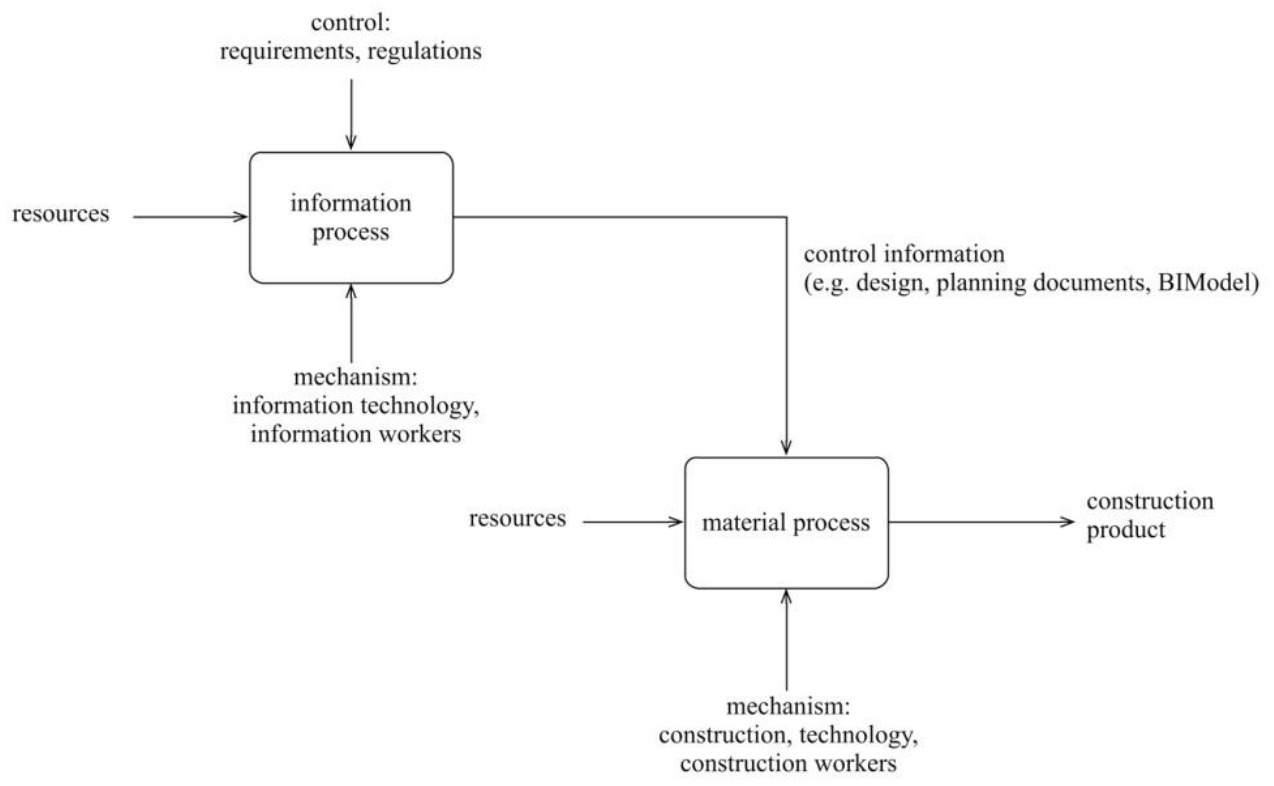

Figure 1: Generic relation between information and material processes.

\section{Problem statement}

The hypothesis is that technological change in the area of information and communication technology is resulting in a change in the abstractions that we use to understand human activities during the construction processes, particularly those which are information intensive. The current understanding can be used to explain the 
construction processes since the introduction of modern construction drawings in the 15 th century. Since then a lot has changed on several levels.

- On the processing level, processing power and storage capacity are growing exponentially.

- On the representation level, designs are represented as structured, digital, engineering objects and not as geometric elements such as lines.

- On the collaboration level, the change is related to ubiquitous high speed wired and wireless communication networks and broad, cheap availability of the internet that enables not only information exchange among software but also person-to-person communication.

The particular tipping points in construction design are technologies for building information modelling (Eastman, Teicholz, Sacks, \& Liston, 2011) and mass person-toperson communication of Web 2.0 (O'Reilly, 2007). These two tipping points were recognized quite early. Zamanian and Pittman (1999) identified Internet Technology as one of the two technologies supporting the modern distributed collaboration; the other being object databases, which essentially are the foundation of BIM.

In summary, the possibilities that people have to connect to other people in real time or access the work they or others did are orders of magnitude higher than in the past when the paradigms for the understanding industrial processes were established. This is creating a gap between the framework we have for understanding construction information activities and what is actually going on in the industry - the social aspects play no role in the current framework.

The issue now is how to understand the AEC (architecture, engineering and construction) industry in this new technological context and how to understand the role 
of the current and future technology, taking into account the new communication realities on one hand and the traditional material nature of the construction industry's end product (such as house, factory, bridge, dam) on the other. Particularly affected parts of the AEC industry are those dealing with information - such as construction design, planning and management. The construction information activities are the focus of our work. Therefore, the goal is a new, different, richer framework.

\section{Paper structure}

The structure of the paper and the flowchart of the research are presented in Figure 2.

The point of departure is the existing understanding of construction design and recent technological developments. A gap has been identified and a goal set to create a new framework. This has been covered above.

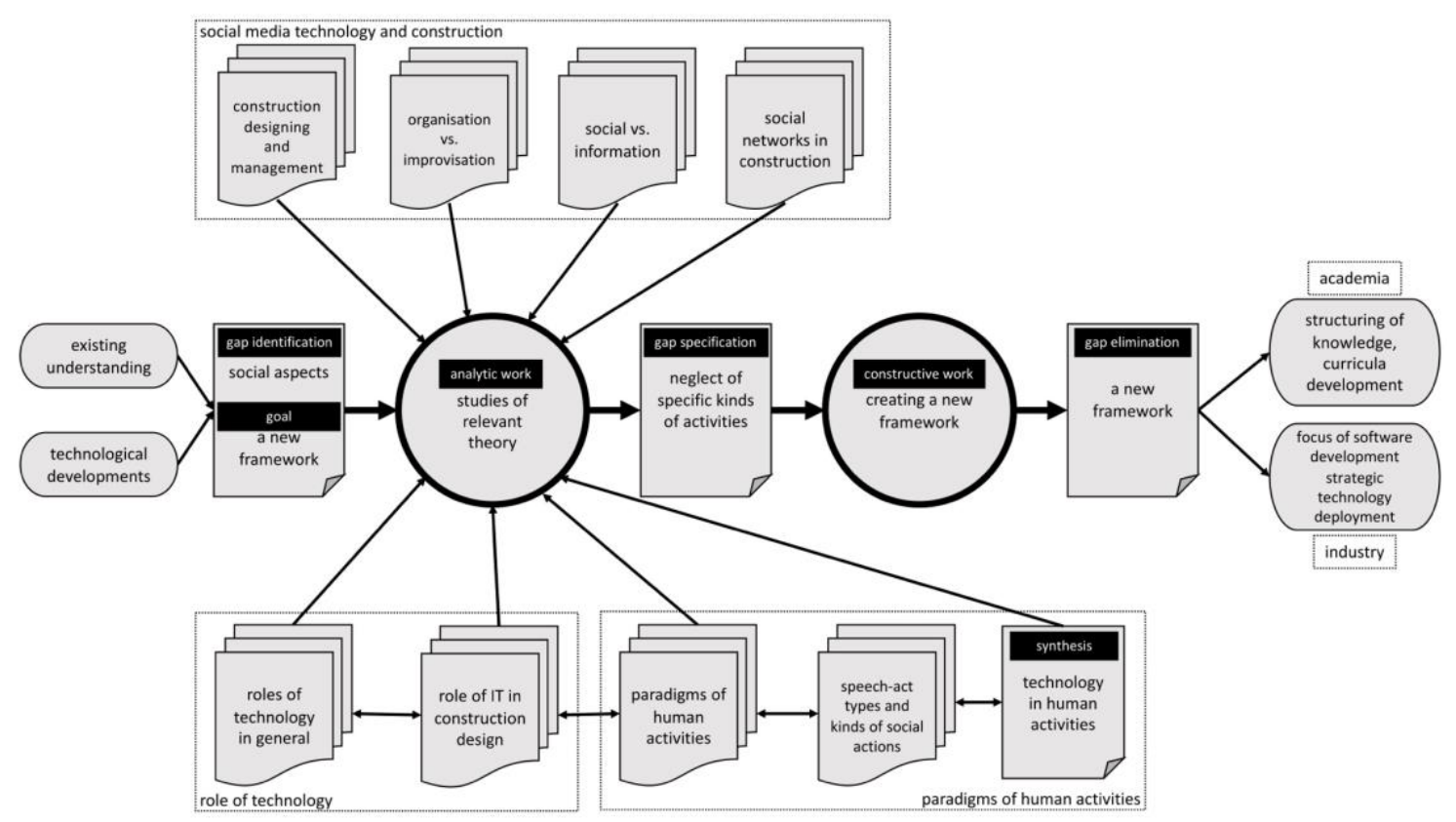

Figure 2: Flowchart of research process and paper structure.

This is followed by the detailed analysis of the gap in three parts. First, (Figure

2 , bottom left) role of technology in general and role of information technology (IT) in construction design. The position is that the current paradigm is too concentrated on one of at least three understanding of technology - technology as a tool (Figure 2, bottom). 
Next (Figure 2, bottom right), the problem is approached from another angle: how peoples' actions are understood, what paradigms of human activities exist according to theory and how their communication and collaboration can be classified. We rely on speech act theory and social action theory. It will be argued that the current understanding is too much focused on examining what is being done as processing but less so as commitment negotiation or reflection in action. It will be found out that only a few of the many theoretically known speech acts and social actions have been addressed and supported by the exiting framework. The synthesis of technology's role in human activities is presented.

Finally (Figure 2, top), more specific issues of construction information activities are examined with respect to the impact of communication and social media. First, the two most information intensive activities of construction, designing and management are examined. Then the impact of the new technology on the balance between the organization and improvisation and social vs. informational aspects of projects is discussed. Finally, social networks in construction are compared to those known in social networking theories.

Based on the studies listed above, gaps are specified and a new framework documented through a series of diagrams. The paper ends with conclusions, discussions, and possibilities of further research.

\section{Roles of technology}

Obscured by the more practical work of making life easier for people, the role of technology has nevertheless been a subject of study since the beginnings of philosophy and has intensified during the scientific revolution. 


\section{General role of technology}

The modern understanding of relations between nature, society and technology starts with Francis Bacon. In his 1626 novel New Atlantis (Bacon, 1626) he is optimistic about the potential of human ingenuity. Karl Marx (Avineri, 1968) saw technology as an opportunity for the liberation of the working class. In the 20th century, philosophers like Heidegger (Dreyfus, 1991) voiced concern of the detachment from the natural, the primal, and the real that technology is causing. The success of technological civilisation is accompanied by a number of sceptics that reject technological determinism (Lanier, 2010; Morozov, 2014) and point to the inherent limitations of technology to change humans and their nature.

In general, the interactions between humans, technology, and the environment can be grouped into three categories each based on the key element - nature, other people, and the person itself.

(1) Much of the philosophical debate was about the relation between nature and technology in the sense that technology imitates nature, changes nature or is an interface to nature (Mitcham, 1994).

(2) More recently, the role of technology in society when used on a grand scale to facilitate human-human interaction was studied (Ellul \& Merton, 1964). It changes human relations and human institutions (Orlikowski, 1992a). Technology is an interface to other people.

(3) Finally, technology is increasingly facilitating human reflective thinking (Schön, 1983) when the person is not in interaction either with nature or with other people (Jonassen, Mayes, \&McAleese, 1993).

The engineering understanding of technology is mostly based on the first category. 
Because of the revolutionary developments of communication technology and the internet, the second element is gaining importance and is being studied on more deeply in this paper.

\section{Role of IT in construction design}

A scheme similar to the above was devised by Negroponte (1975) and confirmed by Kalay (1985) when they speculated about the role of computers in design, architecture and engineering. Computers can be understood as:

(1) a tool - they can be used by a skilled operator to help hum with his tasks;

(2) an assistant - they can do some tasks autonomously as a human helping hand would;

(3) as a medium - they are used for the communication and exchange of ideas and information.

The similarity is that in the interface perspective, the computer as a tool is an interface to nature, the computer as a medium is an interface to other people and also to oneself. The role of the computer as an assistant elevates it to an intelligent partner of a human engineer and is a goal of artificial intelligence research.

\section{The relevance of social sciences}

The lowest common denominator of all thinking was that technology is an important element of what people do. A way to look at this is through the paradigm of a sociotechnical system (Baxter \& Sommerville, 2011), a system that has both humans and technology as building blocks and that has to be studied from the perspective of both engineering as well as social sciences. This paper relies heavily on the findings of both. 
In order to reflect on the general and early ideas of the role of technology described above, one can resort to social, group and analytic theories (Kaplan, 2009). A variant of the social theory is the structuration theory (Giddens, 1984) and the corresponding structurational model of technology (Orlikowski, 1992b) which found one of its first uses in the study of the phenomena of early groupware tools (Orlikowski, 1992a). These tools can be considered as the forerunners of the collaborative Web 2.0.

The structuration theory supports the idea of convergence between the social and the material. Orlikowski (2007) writes that "the social and the material are considered to be inextricably related - there is no social that is not also material, and no material that is not also social". In the context of modern engineering and architectural design this can be paraphrased into "the social and the informational are considered to be inextricably related - there is no social that is not also informational, and no informational that is not also social"'. The informational is building information models (BIM). The social is the social networks in which information models are created and used.

In summary, technology is a defining part of socio-technical systems. Changes in technology cause changes to the whole system. However, the system is an abstraction that is invented to explain, organize and manage the complexity of reality. To create and understand systems, a framework, defined as " $a$ set of beliefs, ideas or principles that is used as the basis for examining or understanding something" (Framework, n.d./a) or as "the structure of a particular system" (Framework, n.d./b), is useful. It defines key elements of the system and their relations. After the technological change, the old framework may not be the most useful anymore. If the major abstractions of the framework are changed, this is called a paradigm shift (Kuhn, 1962). This paradigm 
shift can be witnessed at the time of writing due to the communication technology aspects of the Internet, in construction and elsewhere.

\section{Paradigms of human activities}

The reason for the existence of the socio-technical system called the construction industry is the shaping of the built environment. In this system people use technology as tools, as a medium or as an assistant (as explained above) to get things done. Getting things done can be modelled in different ways: as (1) processing, (2) negotiating commitments or (3) reflection in action (Turk, 1998). After they are described in this section, their implication on designing and project management is addressed in the last two subsections.

\section{Processing}

The prevailing paradigm to understand what people do is that of processing. The idea that everything that engineers do is processing inputs into outputs is so entrenched that it is often not seen as only one of the possibilities. And indeed, a lot that happens on the construction site and in the offices could hardly be thought about in another way. From the input of concrete, steel, brick and mortar the output - buildings and structures - are built. A more elaborate model such as the IDEF0 (NIST, 1993) would also include controls and mechanisms. The control for the construction of a building would be its design and the mechanisms would be the people and the machines that are used during its construction.

Björk (2002) introduced a distinction between the information and material processes (Figure 1). The result of the information processes is information, which is ultimately used to control the material processes. In the traditional building process, the design and planning activities result in just that -drawings, plans and reports that 
control the building process. In the building information modelling approach, a digital replica of a building and building process is created. It has also been called the digital twin (Whyte \& Hartmann, 2017).

A rich and precisely defined digital representation of the building and the process that will end up in creating this building is calling for precise definition of the processes in which this information is created. No wonder that much of the work after the adoption of the BIM process has been dedicated to the study of processes that will create all that information in an orderly and planned manner (Babič, Podbreznik, \& Rebolj, 2010; Cerovšek, 2011; König, 2018; Beetz, Borrmann, \& Weise, 2018; Ustinovichius et al., 2018; Gade, Gade, Otrel-Cass, \& Svidt, 2019; Uusitalo, Seppänen, Peltokorpi, \& Olivieri, 2019).

What used to be parsimonious, on-demand, just in time communication on a need-to-know basis is becoming a pre-defined, detailed process plan to create all the information at sufficient level of detail for each of the defined stages in the life-cycle of the building product. Extensive theoretical and practical work is needed to define information needs of the BIM process (Azhar, 2011), information delivery protocols (Hooper \& Ekholm, 2012), levels of developments (Arayici, Egbu, \& Coates, 2012) etc. A good illustration is the RIBA Plan of Work (2013) and RIBA Small Project Plan of Work (2016).

In a sense, the hope that the building processes can be properly planned in advance by some higher wisdom compares to the idea that the economy of a country or the world can be planned in advance for optimum results. An opposing view (von Mises, 1949) claims that there is too much uncertainty and too much information to be taken into account and that best results are achieved if humans are free to act and select the best means to achieve the goals. 
The proposed social-product-process framework of construction seeks to complement the rigid, planned, and defined process-oriented view with a flexible, improvised "commitment negotiation" view. It is compatible with the novel construction management theories addressed in subsection "Influence on management".

\section{Negotiating commitments and meanings with speech acts and social action}

In contrast to processing, two other paradigms have been proposed. The action workflow paradigm (Medina-Mora, Wong, \& Flores, 1993) is based on the idea that "negotiating commitments" is an important human activity. It has been used to analyse activities particularly in service oriented industries, in public administration (Thomson \& Perry, 2006), medicine, tourism, but also construction (Turk, 2000). Because of its conversational nature it was seen as supportive of cooperative work and selforganisation (Schäl, 1995). The integration capacity and support for self-organization is a welcome feature for an industry as dynamic as construction.

Theoretically, the "negotiating commitments" paradigm is based on the speech act theory of Austin (1962) and Searle (1969). It claims that the primary motive for communicating is not the exchange of information but getting the listener to respond with some action. Searle (1969) classified the speech acts into five categories. They are listed from most to least obviously leading to consequences:

- Declaratives change the world immediately because the change is in information.

- Commissives commit the speaker to do something.

- Directives direct the hearer to do something.

- Assertives claim something about the state of the world. 
- Expressives say something about the speaker's state of mind. The theory also distinguishes between the semantics and pragmatics of the act - the semantics being the literal meaning and the pragmatics the goal of the speaker.

Another scheme was presented by Habermas (1984). In his Critical Social Theory aimed at structuring the critique of society, he distinguishes between four categories of social action:

- Teleological action where the purpose-oriented action is directed at the physical world.

- Normative action fulfils reciprocal expectations and the conforming of behaviour to common norms and values.

- Dramaturgical action is where the performer is explaining himself to the audience.

- Communicative action is where actors seek understanding in order to coordinate their actions.

Adriaanse, Voordijk and Dewulf (2004) used that schema to classify social activity in the groupware software. Both schemes will be used later to identify the gaps in the current understanding of construction communication - focusing mostly and insufficiently only on the Searle's declaratives and Habermas' teleological actions and ignoring all others.

\section{Reflection in action}

The reflection in action paradigm looks at the reflective processes in human mind (Schön, 1983). Schön explains their creative work in design through the reflection-inaction and reflection-on-action. He echoes the works of Heidegger (Harman, 2002) and 
others who stressed that many decisions that people take are pre-rational when taken but can be rationalized when challenged for an explanation. The first reflection happens in action, the second on action. The line of research that Schön opened tries to explain the activities that are less predetermined and more improvised. Contemporary ideas on the evolution of language (Haidt, 2001) claim that language has developed to explain decisions to others and not to reason about the decisions in one's mind.

\section{Technology in human activities}

In this and the previous section three paradigms of human activities and three roles of technology have been identified and can be synthesised as follows:

(1) The processing paradigm places a person as a mechanism that will take part in a process. The process is changing inputs into outputs and creating value. The person will use technology. It corresponds well to the role of the computer as a tool of that person.

(2) In the action workflow paradigm people communicate and the role of technology is to assist in that communication. The role of information technology is that of a medium.

(3) In the reflection in action the person is primarily thinking about the problem alone. He or she may use tools, assistants or media to think better. Tools include design software. An artificial intelligence software would qualify as an assistant. A screen or a drawing board would be a medium for ideas which are reflected upon.

More interesting, however, is the collective reflection in action (Johnston \& Fells, 2017). An interesting question is to what extent can communication that includes the reflection-on-action (and is therefore rational and methodical) be complemented with 
communication about the reflection-in-action. It seems that with advanced communication technologies a state is being approached where a group or a team becomes a unit that requires less communication of structured information as discussed in subsection "Influence on management".

A state where a group reaches the collective reflection in action presupposes internalization of the group's goals. A research in social psychology (Festinger, 1953) showed that members of the group react in two different ways to internal differences. They either internalize the group attitudes, values and goals or simply comply with the requests. Which of the two behaviours prevails depends largely on social interaction within the group. It can be assumed that if the relationships among team members are tighter, as in rich social networks, internalization is more likely.

\section{Social media technology and construction}

First, the two most information intensive phases of construction are examined and then the impact of social media on construction technology is revisited with a focus on communication and social media technologies.

\section{Designing as communication}

Several authors have claimed that design is actually a communication problem (Mitchell \& McCullough, 1995; Paulini, Murty, \& Maher, 2011; Gardan, 2012).

Gabriel and Maher (2002) examined the effect and significance of different communication channels in collaborative sessions between architects. They work under the assumption that "architecture is primarily about communication". They argue that successful computer-mediated collaborative design (CMCD) does not necessarily mean emulating close-proximity environments. In their hierarchical coding scheme of verbal communication in collaborative design they echo Habermas and Searle (see above) and 
distinguish between communication control, communication technology, social communication and design communication. The latter can be about design ideas, design task and design scope. They found that face to face communication was most spontaneous and computer mediated communication with limited availability of communication channels was least spontaneous but most dominated by discussions about design.

The work of Lloyd and Deasley (1998) builds on the tradition of acts and models designing as negotiating and communicating meaning. They write that meanings are constructed and renewed as much through social interaction as by individuals in isolation.

\section{Influence on management}

Management is about managing what people do and management theories are, naturally, influenced by paradigms of human activities. The literature (Johnston \& Brennan, 1996; Molin, 2003) generally distinguishes between the conventional planning approaches and alternative approaches. The conventional planning approach assumes that the processes leading to fulfilling the goal can be predetermined and that this will lead to efficient execution of a project. Using the term process itself makes this approach very compatible to understanding the work as processing (see subsection "Processing"). A key element of this understanding is that a complex project can be decomposed into manageable sub-processes (Project Management Institute, 2017) and that the sum of manageable small elements is itself manageable. Experience, however, shows this may not be true for complex projects (Koskela \& Howell, 2002).

Alternative approaches understand projects as something emerging. Williams (2005) is suggesting that "for projects that are complex, uncertain, and time-limited, conventional methods might be inappropriate, and aspects of newer methodologies in 
which the project 'emerges' rather than being fully pre-planned might be more appropriate". The project emergence shifts the focus of communication types from teleological to normative, dramaturgical and communicative. The management of the "emerging" rather than "pre-planned" projects focuses on organizing (Johnston \& Brennan, 1996) rather than planning. Organizing includes setting up the right kind of environment for learning and emergence to occur by providing a proper project infrastructure. This includes the social infrastructure. It needs to be properly integrated in the organization, not replace organization with improvisation. Conceptually this infrastructure will be described in the section "The new framework".

\section{Organization vs. improvisation}

In many of the discussions above there has been emerging an alternative between the organization and improvisation or between the stability and flexibility. The process approach offers limited room for the improvisation and flexibility. The action workflow offers more. The reflection in action in a group setting allows for the collective reflection in action.

Very early researchers of general-purpose information systems noticed the contradiction between efficiency and flexibility. Allen and Boynton (1991) noticed that information systems are disablers of flexibility. They force the business processes into the mould enforced by the information system. They claim (ibid.) that " $a$ single, monolithic application system will not allow future organizations to reap competitive advantage for long."

This is a timely reminder of limitations of monolithic building information models and monolithic process models. Allen and Boynton (ibid.) introduce the idea of high- vs. low-road information systems, the first being centralized and organized, and the second decentralised and improvised. They are finding pros and cons in both 
approaches. Within that understanding, the proposed framework will try to bridge the gap between the high and the low road of construction information systems to offer the AEC professionals the best of both worlds. Figure 3 illustrates the two current construction communication architectures, the low-road on the left and the high-road on the right.
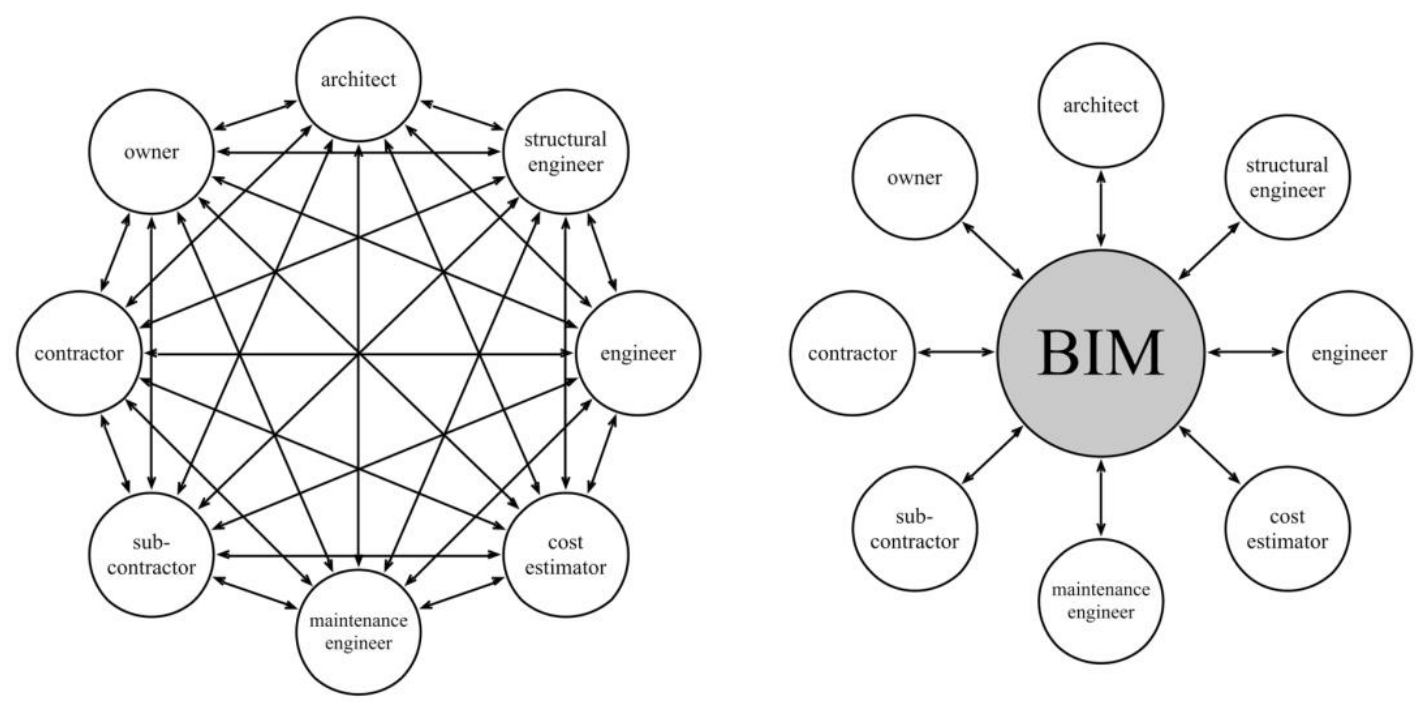

Figure 3: Low (left) and high (right) road to information systems in construction.

Löfgren (2005) is finding that "the constant changes of plan and unanticipated events in the production process at construction sites result in communication patterns that are dynamic, spontaneous and informal. Most of the existing ICT tools do not sufficiently support informal communication for powerful collaborative problemsolving, management of site resources, handling of parallel process activities and do not correspond to the basic needs and work patterns at the construction sites". Dossick at al. (2014) are drawing attention to the "messy talk" that occurs during construction projects and expose the limitations of BIM centred communication exchange.

Chinowski at al. (2008) framed the issue as two perspectives - traditional that tries to pre-plan tasks and develop schedules as detailed and as correct as possible, and the new paradigm that aims at creating high performance teams: "The engineering 
approach has favoured the development of an optimum plan as the path to effective project management". In their work they "reemphasize the need to develop high performing teams by recognizing the importance of the project network. This recognition is formalized in the social network model of construction".

In their social model (ibid.) they distinguish between dynamics and mechanics components; the dynamics addressing values, trust, reliance and experience, the mechanics addressing knowledge exchange, information exchange and communications. They note problems of construction social networks that include network instability, rapid movement from network formation to network collaboration, and the contractual relationships that serve as a barrier to the free exchange of information.

All of this leads project management away from the conventional pre-defined management to the alternative approaches that have better results in uncertain, complex, dynamic, time limited conditions.

\section{Social vs. informational}

The dilemma comes in many shapes. Bucciarelli (2003) identified two postulates defining engineering.

- In real world: "Engineering design is a social process requiring the participation of different individuals having different competencies, responsibilities and technical interests".

- In engineering education: "Engineering is an instrumental process requiring the application of established, rational scientific theory in the development of new products and systems for the benefit of humankind."

He is investigating how engineering education could be improved to make the two 
worlds compatible and is suggesting project-based learning as a partial solution.

Cerić (2014) addresses the problem of asymmetric information in construction projects. Specifically, the following types of information asymmetries apply for acting persons: hidden characteristics, hidden information, and hidden intention. Respectively, these three types of information asymmetries generate the following risks: adverse selection, moral hazard, and hold-up. It can be assumed that a shared BIM model would solve this problem because everything is available to everyone, however, information can also be hidden in an overload of information.

Wikforss and Löfgren (2007) introduced the subject field of Project Communication. They argue that "to solve the practical problems that the industry is encountering (...) the perspective must be widened so as to include information and communication technology from an organizational and management viewpoint". The broader view of the project communication is the project's social network in this paper.

Cheng et al. (2001) enumerate four basic types of construction networks as shown in Figure 4. The research and commercial effort of the last two decades has been focused on BIM as a centre of gravity around which actor networks get established (see Figure 3, right). Linderoth (2010) studied the role of BIM and particularly how these networks can be preserved when moving from one BIM project to the next.

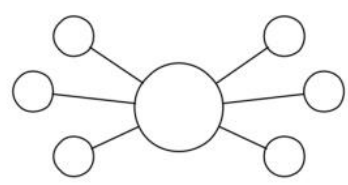

formal partnership

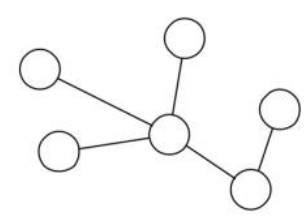

contractual relationship

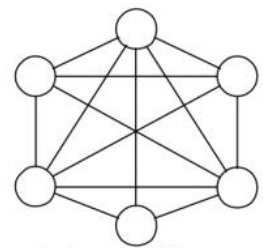

informal alliance

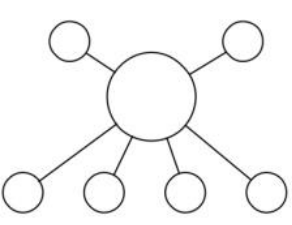

project joint venture 
Figure 4: Basic types of construction networks (Cheng et al.,2001)

When Figure 4 is compared to Figure 3, a gap between the known communication architectures and the two used in construction becomes apparent. It can clearly be seen that the basic idea of BIM corresponds well to two of the four topologies while it fails to match the other two. All four topologies in Figure 4, however, evolved naturally. This gap is also addressed by the framework presented in this paper.

It is also important to note that the graphs are different if different networking is taken into account. The networks include at least communication networks (who talks to whom), contractual networks (who has contracts with whom), financial networks (who pays whom, similar to contractual), and information sharing networks (who shares what). The social network is the most generic of them all.

\section{Social networks in construction}

Before inexpensive paper was introduced and technical drawing techniques were invented the whole construction process was managed by a single master builder having the knowledge and responsibility to carry out a project from the start to the successful finish (Zanini, 2007). This was also an era when the only method of communication between the parties involved was mouth-to-mouth with practically no documentation and information in the modern sense (Jacobs, 2016). Later communication with drawings allowed construction projects to became more and more complex involving more and more participants. Nowadays, the construction industry is a complex system in demand of a project-based, collaborative, relationship-oriented approach to management (Costa \& Tavares, 2014) where project teams consist of various parties with different levels of expertise, resources, and business interests (Abduh \& Skibniewski, 2003). This multi-party nature of the industry creates challenging environment where project success depends mostly on timely transfer of information 
among the parties involved (Rojas \& Songer, 1999). Communication channels established during the construction project depend mostly on the composition of the project team as well as the agreed communication paths. What is more, they also depend on the phase or activity in which the project currently is (Emmitt \& Gorse, 2003). New networks of actors are generated every time a project is either ending or starting, making the transfer of experiences, knowledge and information derived from previous projects to new ones even more challenging (Costa \& Tavares, 2014).

In general, the AEC industry incorporates all types of social and communication network connections. The topology of the network used in any individual situation depends on the context in which the examined construction process is seen and specifies the level of connectivity of individual nodes in the established network (see Figure 4).

It is worth noting that in an area such as construction, the cohesion is often reduced since the associated parties rather focus on individual goals than on the overall network success (Chinowsky, Diekmann, \& Galotti, 2008). Nevertheless, Costa and Tavares (2014) noted that the assumed benefit generated for any member of a social network is proportional to the value of interactions among all other members of the network.

Thorpe and Mead (2001) found that some members of the construction project team have a critical role in the communication network because they have the highest frequency of communication with other project members and therefore the highest level of centrality. Chinowsky et al. (2008) emphasized that the isolation of key individuals results in overcentralized decision making, lack of information, knowledge integration and trust. On the other hand, Alarcón et al. (2013) measured the diameter of the information flow network in a construction project as six, meaning each message an individual would like to send to everyone in the network has to pass six different 
people. Even if everyone used the shortest existing path to transfer information, the average measured diameter would still be 2.6.

In addition to classic emphasis on communication as the driver for project success, Chinowsky, Diekmann \& O’Brien (2009) gave equal prominence to social relationships and noted in their model that issues regarding communication and trust among key project personnel resulted in poor project performance. Similarly, Xue, Shen, Fan, Li \& Fan (2012) found organizational culture and human related subjective factors significant for development of any information system supporting collaborative work. Chinowsky et al. (2008) recognized the importance of the project network when developing high performing teams, aiming to move beyond reactive communication and information sharing to proactive knowledge exchange. They also stressed that informal networks are critical to a construction project success due to their agility and flexibility in the case of unexpected events.

Costa and Tavares (2014) introduce the social e-business concept as "innovative e-business vision, which integrates web-based collaborative tools, emphasizes the importance of social capital and social networking, and enhances the role of supply chain management". They propose a satellite network model, basically a network of networks that span organizational and project lifecycle boundaries. The method could be used for structuring larger networks.

To summarise, researchers could not avoid studying use of social networks in building and construction processes. The goal of this paper is to present a framework that would extend our understanding of the AEC profession and its use of technology with social networking.

\section{The new framework}

In the previous sections, an argument has been laid out that the prevailing paradigm - 
that construction products are the results of construction processes performed by actors - is oversimplified and limited.

\section{Gap specification}

The existing framework fails to take into account the recent technological progress in internet technology and social media. It practically fails to support notions of designing as communication; fails to support more flexible, even improvised forms of management; focuses on informational and ignores social components of collaboration, and accommodates only two of many communication networks known in the communication theory.

Theoretically, it takes only partial stock of findings in philosophy, linguistics, social science, communication and design theory. It only accommodates one of the possible uses of technology - that of a tool; neglects the "medium" aspect of the role of technologies of design sciences; focuses on processing and neglects commitment negotiation and reflection in action paradigms of human activities. Particularly the speech-acts other than declaratives (as per Searle) and other than teleological actions (as per Habermas) have been largely ignored.

\section{The new framework}

The task now is to present an inclusive, holistic framework that would include all the missing elements summarised above and explained in depth in the previous three sections. It will be created as an extension to the prevailing product-process paradigm. If will be presented in Figures 5-7.

The point of departure is the most generic relation between the information and material processes (Figure 1) as modelled by Björk (2002). In the IDEF0 notation, the rounded rectangles denote processes. The arrows denote the relations among the 
processes. The arrow pointing to the process from the left denotes the inputs, the one from the top the controls or constraints, and the one from the bottom the resources that (unlike inputs) are not transformed into outputs in the process. The arrow exiting on the right of the rectangle denotes the outputs. The basic message of Figure 1 is that information processes (such as designing and planning) create information that controls material processes (excavating, building, demolishing etc.). The information processes are elaborated on in Figure 5:

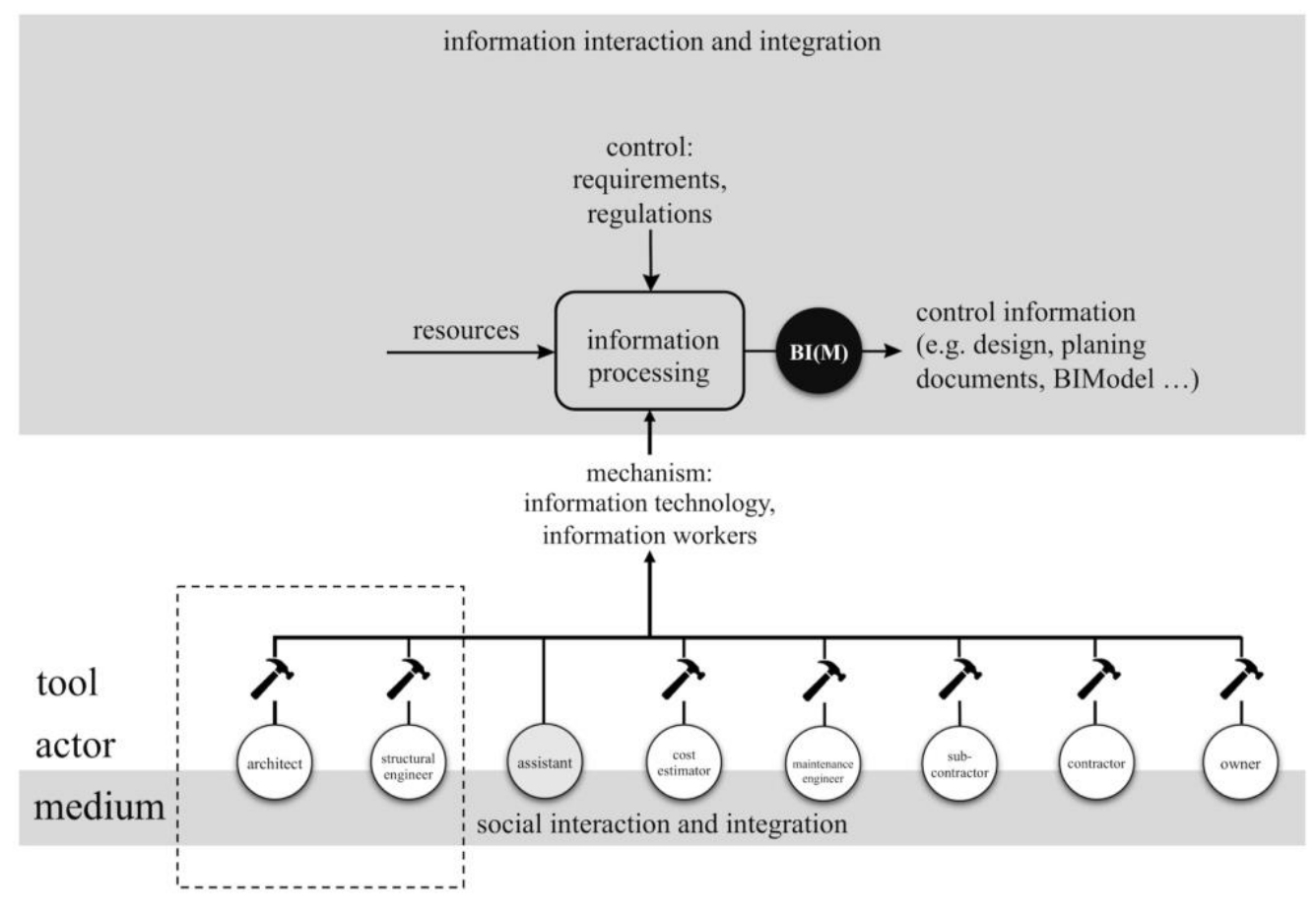

Figure 5: Highest level view of the framework-mechanisms of information processes.

- The main result of the information process is building information. It can have the form of a building information model as in Figure 3 (right), but not necessarily, which makes the Figure 5 generic. Information processes as well as control information existed before BIM.

- At the bottom of Figure 5, the mechanisms are elaborated on. These include human actors (architect, structural engineer ...), non-human actors (assistant) and tools (depicted as hammers, but, in reality, these would be software tools). 
And finally, there is a medium layer that enables social interaction among the actors. Thus, all three Negroponte's roles of technology - tool, assistant and media - have been accommodated in the framework.

The relation between two actors (the dashed rectangle in Figure 5) is zoomed into in Figure 6. It is theoretically based on the three paradigms of human activities: processing, commitment negotiation and reflection in action seen in the centre. It demonstrates again that integration can generally be achieved on two tiers. On the top tier there is the traditional product-process integration. Recently this one has been mostly related to building information modelling. The bottom tier is about integration via social collaboration that takes place when negotiating and accepting commitments. The reflection in action is less relevant as it is done in isolation. Looking at this part of the framework from the project management point of view, both approaches to management have been accommodated: the top tier presents traditional approach to project management, while the bottom tier corresponds well to the emerging project management approaches (see subsection "Influence on management").

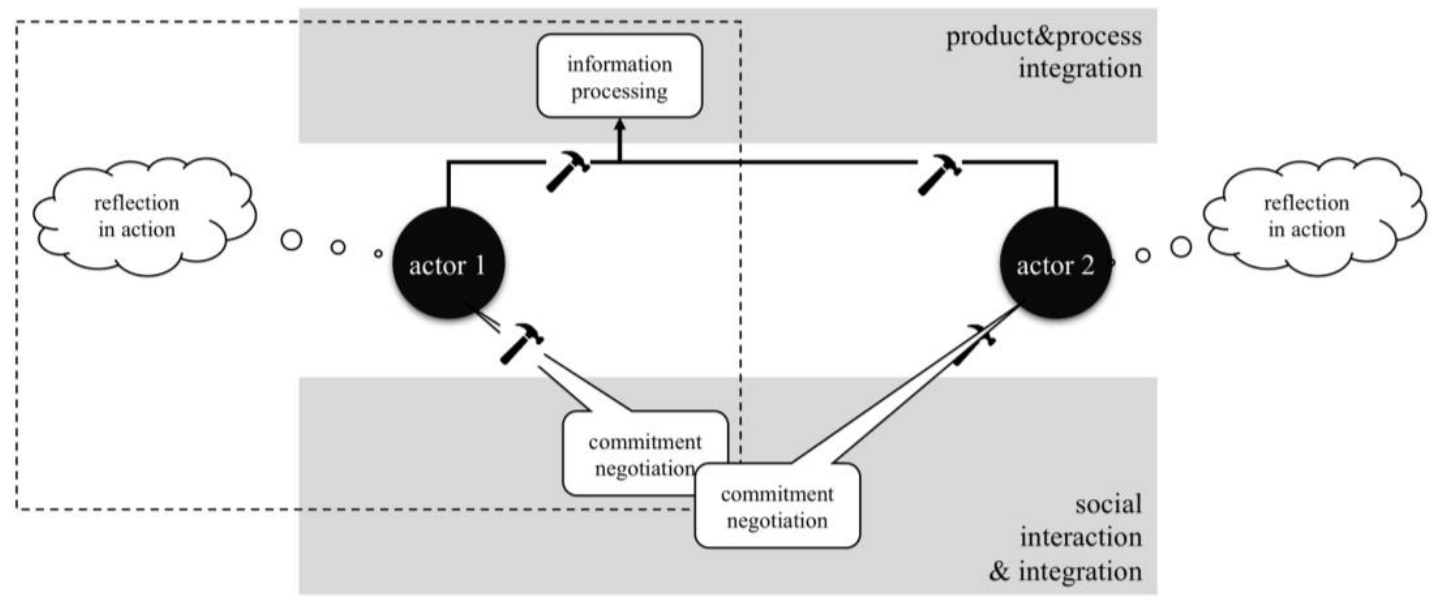

Figure 6: Framework zoomed into the relations between two actors.

The last zoom into the framework is into the dashed rectangle of Figure 6 into Figure 7. It is focusing on a single actor and her commitment negotiation activities. 
Three kinds of classifications have been chosen: 1) by the kinds of social action, 2) by the kinds of speech act and 3) by the action workflow stages. The social collaboration tier (bottom) complements the kinds of social action (as per Habermas) and possible speech acts (as per Searle) and supports the missing stages of the action workflow loop. The typical information exchange in the product and process tier, however, only supports (in black font) acts which are in Habermas' view teleological (changes to the digital world), in the view of Searle declarative (changes in information). They support only the performance stage of the action workflow. The framework accommodates all kinds of social actions.

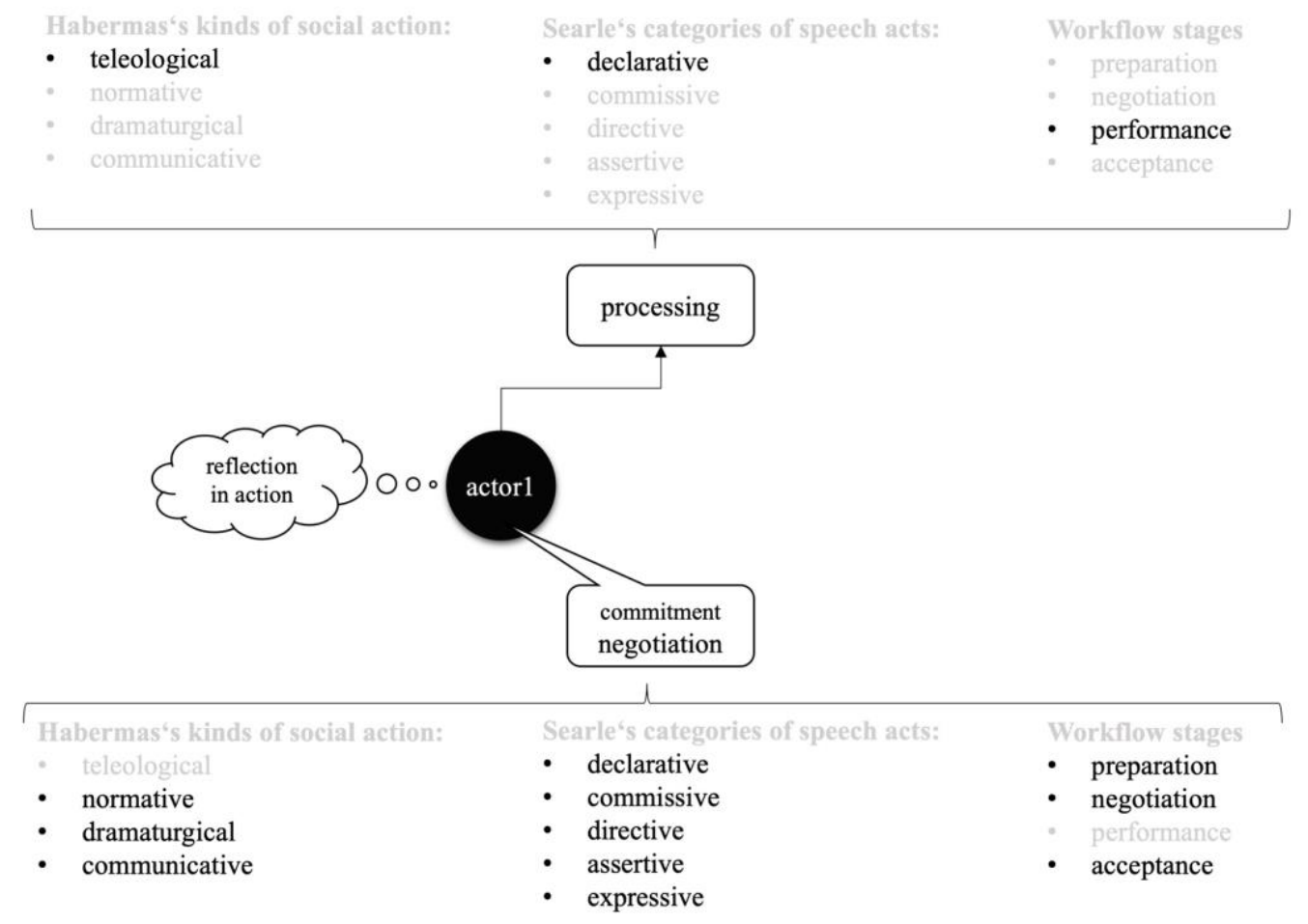

Figure 7: Framework further zoomed in to a single actor, detailing of kinds of activities an actor can perform. Unsupported activities are greyed out.

Thereby it has been demonstrated that the social collaboration activities enabled by the social media technology complement the information processing activities. Both kinds exist in practice, both are needed and both tiers of information technology support 
are needed to support construction projects. The fact that social media tools are used by construction professionals on a daily basis provides an empirical validation.

\section{Conclusions and discussion}

Progress in building profession requires specialization. Firms specialize, they hire and train specialists, software too is specialized. Construction information technology enabled specialisation which - unfortunately - led to fragmentation. Integrating fragmented specialists, processes and information is an important task in organizing building activities and a research topic called "Computer integrated Construction". Social media technology is a powerful tool of integration.

Traditionally, it was the physical building that required for activities to end in a single coherent result. Then the building information model implemented a three or more dimensional digital twin as an element of integration and coherence. In this paper a theoretical argument for the third element of this integrative axis has been given - the social network that connects the persons involved.

The material building, the digital twin, and the (new) social network together form what can be called an axis of gravity. Informally, this is illustrated in Figure 8.

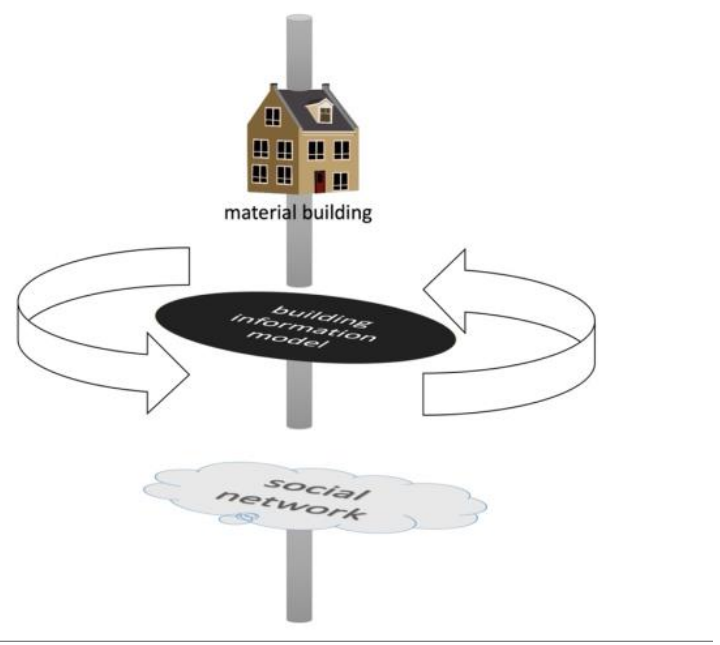

Figure 8: The three elements of the axis of gravity that integrates construction and are preventing fragmentation. 
The social media element should be taken into account in building research as well as in the practice. Design and construction firms should include the social elements of collaboration when organizing and managing the work. If they fail to do so the social interaction will happen anyway, and it is happening anyway. The reason for this is that the product-process centred view fails to capture certain kinds of social actions, speech acts and workflow stages as illustrated in Figure 7. Social networking technology supports the emergent aspect of projects and the (at first glance) chaotic everyone-witheveryone communication (Fig. 3 - left). These activities will take place - the choice is only will they be improvised or preferably organized. The presented framework provides a basis for their organization.

\section{Discussion and further work}

This framework also allows us to structure thinking, teaching, research and development in the field of computer integrated construction into three overlapping areas as shown in Figure 9 (which is based in the central part of Figure 7). The research related to building product modelling ("BIM research") relates to the activities that can be best described as processing. The results are increasingly complex building information models and increasingly complex and detailed building information modelling processes. Next, there is a well-established field of design research or design science that mostly studies how humans reach design decisions either in communication with others or more often while in conversation with the medium such as a piece of paper, computer screen or a 3D model. And finally, there is a topic of social design research that looks at human activities as collaborations among people. The collaboration in information processes is about collaborative working on information as information is passed around - communicated. Not only information describing the product, but many other kinds of speech acts as well. 


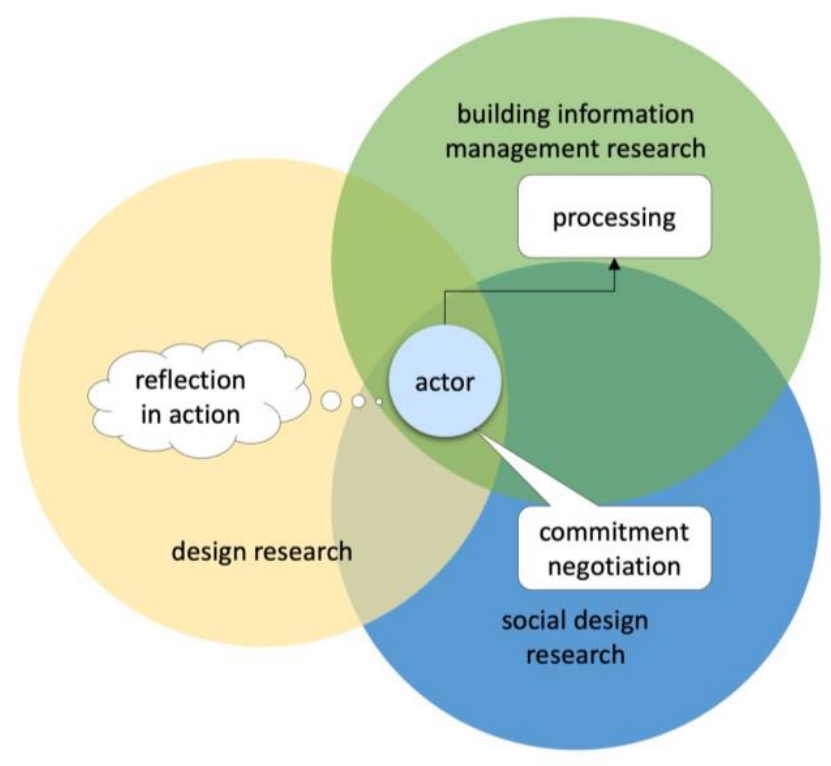

Figure 9: Three areas of computer integrated construction research.

Thereby Figure 9 shows a further usefulness of the framework - to structure teaching and research topics; and points to a third area of teaching and research in addition to building information management and design science that is emerging social design science. It also indicates that a new profession (or task of an existing BIM manager) may be needed to manage the social aspects of collaboration and calls for new topics in the curricula of universities. This need is not self-evident and would require further study of the power of technological populism to achieve collaboration in a selfmanaged way.

One of the issues that the presented framework makes quite apparent is the relation between the layers in Figure 8. Are actors - humans or artificial intelligence agents - the only link between the three layers? Or should there be references into the bottom layer (in the communications among people) about certain parts of the information model? How mandatory and firm should these references be? May those involved in the building process discuss anything or just the building information model? How precisely should communication refer to the elements in the model? Should it address specific (IFC) objects or general, common sense engineering 
concepts? One direction of research would be to observe and measure the existing practices and report how things are being done. The other direction of research would be to construct recommendations, processes and technical solutions for how things should be in an ideal future.

The intuitive answer would be that the top-to-bottom-tier references should be soft and optional so as to preserve some liberty and allow for flexibility and improvisation in the building process.

The framework provides a basis for measuring this optionality. The tools for all three kinds of activities - processing, commitment negotiation and reflection in action are leaving digital traces in the form of log files, emails, social media messages, versioning of models, etc. It should be possible to classify activities and communication acts according to Figure 7. It should be possible to measure the time spent in each of those activities as well as the amount and information content of the data created or exchanged. It would be more difficult to estimate the importance of those exchanges. One would be inclined to believe that the information density is much higher in the upper tier than in the exchanges in the lower tier of communication in Figure 6.

Both tiers are valuable. The work presented here allows for a more structured and systematic examination of information processes in construction. The technical solutions and tools that allow for the complementary co-existence of approaches in Figure 3 might prevent the kinds of information systems that Allen and Boynton (1991) called "disablers of flexibility" and bridge between the "high and the low road" of information systems in construction. 


\section{References}

Abduh, M., \& Skibniewski, M. J. (2003). Utility Assessment of Electronic Networking Technologies for Design-Build Projects. Automation in Construction, 12(2), 167-183. doi:10.1016/S0926-5805(02)00042-0

Adriaanse, A. M., Voordijk, H., \& Dewulf, G. P. M. R. (2004). Alignment between ICT and communication in construction projects. International journal of human resources development and management, 4(4), 346-357.

Alarcón, D. M., Alarcón, I. M., \& Alarcón, L. F. (2013, August). Social Network Analysis: A Diagnostic Tool for Information Flow in the AEC Industry. In: C. T. Formoso, C.T. \& P. Tzortzopoulos (Eds.), 21th Annual Conference of the International Group for Lean Construction (pp. 947-956). Fortaleza, Brazil.

Allen, B. R., \& Boynton, A. C. (1991). Information architecture: in search of efficient flexibility. MIS quarterly, 15(4), 435-445.

Arayici, Y., Egbu, C. O., \& Coates, P. (2012). Building information modelling (BIM) implementation and remote construction projects: issues, challenges, and critiques. Journal of Information Technology in Construction (ITcon), 17, 75-92.

Austin, J. (1962). How to do Things with Words. London, UK: Claredon Press.

Avineri, S. (1968). The social and political thought of Karl Marx. Cambridge University Press, Vol. 619. doi:10.1017/CBO9781139171410

Azhar, S. (2011). Building information modeling (BIM): Trends, benefits, risks, and challenges for the AEC industry. Leadership and Management in Engineering, 11(3), 241-252. doi:10.1061/(ASCE)LM.1943-5630.0000127

Babič, N. Č., Podbreznik, P., \& Rebolj, D. (2010). Integrating Resource Production and Construction Using BIM. Automation in Construction, 19(5), 539-543. doi:10.1016/j.autcon.2009.11.005

Bacon, F. (1626). New Atlantis. In R.-M. Sargent (Ed.), Francis Bacon: Selected Philosophical Works (1999, pp. 241-268). Indianapolis/Cambridge: Hackett Publishing Company.

Baxter, G., \& Sommerville, I. (2011). Socio-technical systems: From design methods to systems engineering. Interacting with Computers, 23(1), 4-17. doi:10.1016/j.intcom.2010.07.003

Beetz, J., Borrmann, A., \& Weise, M. (2018). Process-Based Definition of Model Content. In Borrmann, A., König, M., Koch, C., \& Beetz, J. (Eds.). (2018). 
Building Information Modeling: Technology Foundations and Industry Practice (pp. 127-138). Springer International Publishing. doi: 10.1007/978-3-31992862-3

Björk, B-C (2002). A formalised model of the information and materials handling activities in the construction process. Construction Innovation, 2(3), 133-149.

Bucciarelli, L. L. (2003). Designing and learning: a disjunction in contexts. Design Studies, 24(3), 295-311.

buildingSMART (2018). IfcProcess [technical document]. Retrieved from https://standards.buildingsmart.org/IFC/RELEASE/IFC4_1/FINAL/HTML/sche $\mathrm{ma} / \mathrm{ifckernel/lexical/ifcprocess.htm}$

Cerić, A. (2014). Strategies for minimizing information asymmetries in construction projects: project managers' perceptions. Journal of Business Economics and Management, 15(3), 424-440. doi:10.3846/16111699.2012.720601

Cerovšek, T. (2011). A Review and Outlook for a "Building Information Model" (BIM): A Multi-Standpoint Framework for Technological Development. Advanced Engineering Informatics, 25(2), 224-244. doi:10.1016/j.aei.2010.06.003

Cheng, E. W. L., Li, H., Love, P. E. D., \& Irani, Z. (2001). Network Communication in the Construction Industry. Corporate Communications: An International Journal, 6(2), 61-70. doi:10.1108/13563280110390314

Chinowsky, P., Diekmann, J., \& Galotti, V. (2008). Social Network Model of Construction. Journal of Construction Engineering and Management, 134(10), 804-812. doi:10.1061/(ASCE)0733-9364(2008)134:10(804)

Chinowsky, P., Diekmann, J., \& O’Brien, J. (2009). Project Organizations as Social Networks. Journal of Construction Engineering and Management, 136(4), 452458. doi:10.1061/(ASCE)CO.1943-7862.0000161

Costa, A. A., \& Tavares, L. V. (2014). Social E-Business as Support for Construction E-Procurement: E-Procurement Network Dynamics. Automation in Construction, 43, 180-186. doi:10.1016/j.autcon.2014.03.019

Dossick, C., Anderson, A., Azari, R., Iorio, J., Neff, G., \& Taylor, J. (2014). Messy Talk in Virtual Teams: Achieving Knowledge Synthesis through Shared Visualizations. ASCE Journal of Management in Engineering, 31. doi: 10.1061/(ASCE)ME.1943-5479.0000301 
Dreyfus, H. L. (1991). Being-in-the-world: A commentary on Heidegger's Being and Time, Division I. USA: Mit Press.

Eastman, C., Teicholz, P., Sacks, R., \& Liston, K. (2011). BIM handbook: A guide to building information modeling for owners, managers, designers, engineers and contractors. USA: John Wiley \& Sons.

Ellul, J., \& Merton, R. K. (1964). The technological society. New York, USA: Vintage books.

Emmitt, S., \& Gorse, C. A. (2003). Construction Communication: 1 edition. Oxford, UK; Malden, MA: Wiley-Blackwell.

Festinger, L. (1953). An Analysis of Compliant Behavior. In M. Sherif, \& M. O. Wilson (Eds.), Group Relations at the Crossroads, New York, USA: Harper \& Bros.

Framework (n.d./a). In Oxford Learner's Dictionary of Academic English. Retrieved from

https://www.oxfordlearnersdictionaries.com/definition/academic/framework

Framework (n.d./b). In Oxford Advanced Learner's Dictionary. Retrieved from https://www.oxfordlearnersdictionaries.com/definition/english/framework

Gade, P. N., Gade, A. N., Otrel-Cass, K., \& Svidt, K. (2019). A holistic analysis of a BIM-mediated building design process using activity theory. Construction Management and Economics, 37(6), 336-350. https://doi.org/10.1080/01446193.2018.1533644

Gabriel, G. C., \& Maher, M.L. (2002). Coding and modelling communication in architectural collaborative design. Automation in construction, 11(2), 199-211. doi:10.1016/S0926-5805(00)00098-4

Gardan, Y. (2012). Architectural Design and CAD: a selection of papers from MICAD. New York, USA: Springer Science \& Business Media, Nichols Publishing Company.

Giddens, A. (1984). The constitution of society: Outline of the theory of structuration. Berkeley and Los Angeles, USA: Univ of California Press.

Habermas, J. (1984). The theory of communicative action, Vol. I. Boston, USA: Beacon Press.

Haidt, J. (2001). The emotional dog and its rational tail: a social intuitionist approach to moral judgment. Psychological review, 108(4),8 14-834. doi: 10.1037//0033295X.108.4.814 
Harman, G. (2002). Tool-being: Heidegger and the metaphysics of objects. Chicago (IL), USA: Open Court Publishing.

Hooper, M., \& Ekholm, A. (2012). A BIM-Info delivery protocol. Australasian Journal of Construction Economics and Building, 12(4), 39-52. doi:10.5130/AJCEB.v12i4.3031

ISO (2015). ISO 9000:2015(en) Quality management systems — Fundamentals and vocabulary [Technical description]. Retrieved from https://www.iso.org/obp/ui/\#iso:std:iso:9000:ed-4:v1:en

Johnston, S., \& Fells, R. (2017) Reflection-in-action as a collective process: findings from a study in teaching students of negotiation. Reflective Practice, 18(1), 6780. doi:10.1080/14623943.2016.1251410

Johnston, R. B., \& Brennan, M. (1996). Planning or organizing: The implications of theories of activity for management of operations, OMEGA, 24(4), 367-384. doi:10.1016/0305-0483(96)00016-3

Jonassen, D., Mayes, T., \& McAleese, R. (1993). A manifesto for a constructivist approach to uses of technology in higher education. In T. M. Duffy et al. (Eds.), Designing environments for constructive learning (231-247). Berlin Heidelberg, Germany: Springer.

Kalay, Y.E. (1985). Redefining the role of computers in architecture: from drafting/modelling tools to knowledge based assistants. Computer-Aided Design, 17(7), 319-328. doi:10.1016/0010-4485(85)90165-4

Kaplan, D. M., (Ed.) (2009). Readings in the Philosophy of Technology, Second Edition. New York, NY: Rowman \& Littlefield Publishers.

Koskela, L., \& Howell, G. (2002). The underlying theory of project management is obsolete. In PMI Research Conference 2002: Frontiers of Project Management Research and Applications (pp. 293-301). Seattle, WA: Project Management Institute.

König, M. (2018). Process Modeling. In Borrmann, A., König, M., Koch, C., \& Beetz, J. (Eds.). (2018). Building Information Modeling: Technology Foundations and Industry Practice (pp. 63-78). Springer International Publishing. doi: 10.1007/978-3-319-92862-3

Kuhn, T. S. (1962). The Structure of Scientific Revolutions. Chicago, IL: University of Chicago Press.

Lanier, J. (2010). You are not a gadget: A manifesto. New York, NY: Alfred A. Knopf. 
Linderoth, H. C. J. (2010). Understanding adoption and use of BIM as the creation of actor networks. Automation in Construction, 19(1), 66-72. doi:10.1016/j.autcon.2009.09.003

Lloyd, P., \& Deasley, P. (1998). Ethnographic description of design networks. Automation in construction, 7(2), 101-110. doi:10.1016/S0926-5805(97)000514

Löfgren, A. (2005). Socio-technical management of collaborative mobile computing in construction. In R. Scherer, P. Katranuschkov, \& S-E Schapke, W78 2005. Proceedings of the CIB W78 22nd Conference on Information Technology in Construction. Dresden, DE: Technische Universität Dresden.

Medina-Mora, R., Wong, H. K. T., \& Flores, P. (1993). Action Workflow as the Enterprise Integration Technology, IEEE Computer Society Bulletin of the Technical Committee on Data Engineering, 16(2), 49-52.

Mitcham, C. (1994). Thinking through technology: The path between engineering and philosophy. Chicago, USA: University of Chicago Press.

Mitchell, W. J., \& McCullough, M. (1995). Digital design media. New York, NY: John Wiley \& Sons.

Molin, K. (2003, April). Divided loyalties in project management. In Third European Academy of Management conference. Milan, Italy.

Morozov, E. (2014). To save everything, click here: The folly of technological solutionism. New York, NY: PublicAffairs.

Negroponte, N. (1975). Soft architecture machines. Cambridge, MA: MIT Press.

NIST - National Institute of Standards and Technology, Computer Systems Laboratory (1993). Integration definition for function Modeling (idefo), Draft Federal Information Processing Standards Publication 183 [Technical definition]. Retrieved from http://www.idef.com/wp-content/uploads/2016/02/idef0.pdf Project Management Institute. (2017). A guide to the project management body of knowledge (PMBOK guide) (6 ${ }^{\text {th }}$ ed.). Pennsylvania, USA: Project Management Institute.

O'Reilly, T. (2007). What Is Web 2.0: Design Patterns and Business Models for the Next Generation of Software. Communications \& Strategies, 1, 17. Retrieved from https://ssrn.com/abstract=1008839 
Orlikowski, W. J. (1992a). Learning from notes: Organizational issues in groupware implementation. In Proceedings of the 1992 ACM conference on Computersupported cooperative work (362-369). doi:10.1145/143457.143549

Orlikowski, W. J. (1992b). The duality of technology: Rethinking the concept of technology in organizations. Organization science, 3(3), 398-427.

Orlikowski, W. J. (2007). Sociomaterial practices: Exploring technology at work. Organization Studies, 28(9), 1435-1448.

Paulini, M., Murty, P., \& Maher, M. L. (2012). Understanding collective design communication in open innovation communities. International Journal of CoCreation in Design and Arts, 9(2), 90-112. doi:10.1080/15710882.2012.716850

Rojas, E., \& Songer, A. (1999). Web-Centric Systems: A New Paradigm for Collaborative Engineering. Journal of Management in Engineering, 15(1), 3945. doi:10.1061/(ASCE)0742-597X(1999)15:1(39)

Royal Institute of British Architects - RIBA (2013). RIBA Plan of Work 2013 [work document]. Retrieved from http://www.ribaplanofwork.com/

Royal Institute of British Architects - RIBA (2016). RIBA Small Project Plan of Work [work document]. Retrieved from https://www.architecture.com//media/gathercontent/riba-plan-of-work/additionaldocuments/ribasmallprojectplanofworkonlinepdf.pdf

Searle, J. (1969). Speech Acts - an Essay in the Philosophy of Language. London, UK: Cambridge University Press.

Schäl, T. (1995). Supporting Cooperative Work with Workflow Management Technology. In C. Zucchermaglio, S. Bagnara, S.U. Stucky (Eds), Organizational Learning and Technological Change. NATO ASI Series (Series F: Computer and Systems Sciences), 141, Berlin, Heidelberg: Springer.

Schön, D. A. (1983). The reflective practitioner: How professionals think in action. USA: Basic Books.

Thomson, A. M., \& Perry, J. L. (2006). Collaboration processes: Inside the black box. Public Administration Review, 66, 20-32. doi:10.1111/j.15406210.2006.00663.x

Thorpe, T., \& Mead, S. (2001). Project-Specific Web Sites: Friend or Foe? Journal of Construction Engineering and Management, 127(5), 406-413. doi:10.1061/(ASCE)0733-9364(2001)127:5(406) 
Turk, Ž. (1998). On theoretical backgrounds of CAD. In I. Smith (Ed.), Artificial Intelligence in Structural Engineering: Information Technology for Design, Collaboration, Maintenance, and Monitoring (pp. 490-496). https://doi.org/10.1007/BFb0030480

Turk, Ž. (2000). Communication Workflow Approach to CIC. In Proceedings of the Eighth International Conference on Computing in Civil and Building Engineering (ICCCBE-VIII) (pp. 1094-1101). Stanford, CA: American Society of Civil Engineers. doi: https://doi.org/10.1061/40513(279)142

von Mises, L. (1949). Human action: A Treatise on Economics. Auburn, AL, USA: Ludwig von Mises Institute.

Ustinovichius, L., Popov, V., Cepurnaite, J., Vilutienė, T., Samofalov, M., \& Miedziałowski, C. (2018). BIM-based process management model for building design and refurbishment. Archives of Civil and Mechanical Engineering, 18(4), 1136-1149. https://doi.org/10.1016/j.acme.2018.02.004

Uusitalo, P., Seppänen, O., Peltokorpi, A., \& Olivieri, H. (2019). A Lean Design Management Process Based on Planning the Level of Detail in BIM-Based Design. In I. Mutis \& T. Hartmann (Eds.), Advances in Informatics and Computing in Civil and Construction Engineering (pp. 147-152). Springer International Publishing.

Whyte, J. K., \& Hartmann, T. (2017). How digitizing building information transforms the built environment (editorial). Building Research \& Information, 45(6), 591595. doi:10.1080/09613218.2017.1324726

Wikforss, Ö., \& Löfgren, A. (2007). Rethinking communication in construction. Journal of Information Technology in Construction (ITcon), 12, 337-346. Retrieved from http://www.itcon.org/2007/23

Williams, T. (2005). Assessing and moving on from the dominant project management discourse in the light of project overruns. IEEE Transactions on engineering management, 52(4), 497-508.

Xue, X., Shen, Q., Fan, H., Li, H., \& Fan, S. (2012). IT Supported Collaborative Work in A/E/C Projects: A Ten-Year Review. Automation in Construction, 21(1), 1-9. doi:10.1016/j.autcon.2011.05.016 